\title{
Changing the Approach of How to Teach Computational Methods for Engi- neering
}

\section{Dr. Luz Adriana Amaya-Bower, Central State Connecticut University}

Dr. Luz Amaya-Bower joined CCSU's Department of Engineering as an Assistant Professor in August 2012. Before joining CCSU, she was an Assistant Professor of Mechanical Engineering Technology at New York City College of Technology. Her PhD was granted by the Graduate Center, CUNY for her work on dynamic behavior of multiphase flows in microchannels. Dr. Amaya-Bower earned her undergraduate and master's degrees from City College, CUNY. Her teaching and research interests include multiphase flow systems, computational fluid dynamics, and numerical methods. 


\title{
Changing the Approach of How to Teach Computational Methods for Engineering
}

\author{
Dr. Luz Amaya-Bower \\ 1.amaya.bower@ccsu.edu \\ Engineering Department \\ Central State Connecticut University
}

\begin{abstract}
This paper presents data using several methods of assessing student performance with the new inverted classroom methodology in juxtaposition to the traditional method of delivery. The implemented changes have streamlined course contents and noticeably improved student understanding of the covered material. The pilot course is a three credit, 200 level engineering class which aims to teach students the tools for problem solving, graphing and analyzing engineering data, programming of formulae, and procedures. This class uses Excel and Matlab as the software to implement these tools, and approximately twenty chapters are covered within two different textbooks. The following changes have been implemented in this software-based course: First, the structure of the class was modified. Initially, Excel was taught at the beginning of the semester and Matlab in the second part. This structure did not allow for an effective way of comparing the tools between Excel and Matlab. Currently, the class is taught by topics. In addition, the assignments were modified to follow the new structure. Problems are taken from each book and then combined so students can follow the same methodology as in the class. The next change was to modify the method of homework collection. Initially, homework was collected via email and the student received feedback in writing. It was observed that in many cases that the student neither reviewed their errors nor the provided feedback. Now the assignments are revised by the instructor in each student's computer which allows immediate feedback. The final change was to modify the classroom teaching technique. The "flipped" or inverted classroom model was used. This recent pedagogical strategy has received much attention, as lectures are now delivered via computer videos and watched at the student's leisure while class time is spent with the instructor assisting in problem-solving activities. This method has also allowed more class time for the instructor to interact one-on-one with each student. Implementation and assessment data for a pilot class which uses all these changes is presented. The results show a positive improvement in the student outcome compared to previous offerings of this course. In addition, a series of surveys were distributed to obtain feedback and observations from the previous and current students. In general, the findings show that the current methodology can be expanded to other classes throughout the curriculum.
\end{abstract}




\section{Introduction}

The main goal of an educator is to provide knowledge and experience to the students through different teaching techniques. Developing and improving these techniques is an area that has been studied for many decades and will continue evolving for many years to come. As an educator, one has to find teaching methods which best fit the subject matter and provide a learning experience that eventually will improve the professional practice ${ }^{1}$. In recent years, studies have shown that for engineering, mathematics and science there has been a significant shift to move away from a classical lecture-based paradigm towards a learner-center paradigm ${ }^{2,3,4}$. The latter is an umbrella that covers a wide range of instructional techniques which include but are not limited to active and collaborative learning, inquiry-based learning, problem-based learning, project-based learning, case-based learning, and research-based learning. The common factor between all these methods is that the student develops knowledge through the gathering and analyzing of information.

Educators who employ the learner-center approach are required to develop activities that meet the goals of each specific subject while enhancing the learning experience of the student. The development of these activities is a continuous and progressive process. In general, a class and its activities are designed based on the topics to be covered, the goals and outcomes, and the student's learning level. However, as the class progresses, it is normal to realize aspects which need to be changed or that can be improved for future semesters. This is a very common cycle in education, there is never a perfect method for a particular class, but there is always room for advancement.

The successful implementation of any learner-center approach requires adequate amount of time to complete three main steps: introduction, learning activity, and review. Unfortunately, most classes have a very extensive syllabus to be covered during the semester, which does not allow the performance of all three steps during class time. Traditional pedagogy mainly uses the contact time to do the introduction and the review steps, and the learning activities are done as homework assignments. Needless to say, the fundamental components of any learner-center approach are the learning activities, which in many cases are challenging and difficult for the students to complete on their own. Therefore, students do not take full advantage of the benefits of the class. In recent years, the "flipped" or inverted classroom (IC) model has been introduced to allow more class time to be devoted to the learning activities while the introduction of the topic is disseminated by various techniques outside of the classroom setting ${ }^{5,6}$. The most common technique is to provide students with videos which cover the fundamental concepts, show examples, and prepare students to solve problems and performs activities that will reinforce the information learned.

The flipped classroom model has been implemented in a wide variety of Engineering, Math and Science classes, but this model is not limited to any particular subject area. For example, Lage et al. ${ }^{6}$ presented the use of this method in an Economics class at Miami University. This study indicated the positive response of the students, and also expanded on the possibility of attracting a higher diversity of students in this field by using this pedagogy. Gannod et al. ${ }^{7}$ used the flipped model in a Software Engineering course at Miami University. The model was originally introduced in a special topics class on service oriented architecture (SOA); however, due to the positive results, the model was extended to other classes within the curriculum. Toto et al. ${ }^{8}$ showed how the inverted model was used in an Industrial Engineering course at Pennsylvania 
State University. In general the results were positive, but it was also indicated that the implementation of this model required a learning curve to constantly improve the materials distributed to the students. This study emphasized that the key for success is pre-planning. Zappe et al. ${ }^{9}$ used the inverted class in an architectural class at Pennsylvania State University. This study provided useful suggestions to improve the learning experience: first, students must complete a quiz after reviewing the material and before attending class; second, keep videos between 20-30 minutes long, to ensure students remained focused; third, review the content of the videos before starting the class activities; fourth, adding multimedia features to lectures to create more engaging material. Talbert ${ }^{10}$ implemented an inverted class model in an introductory programming class, "Computer Tools for Problem Solving," using Matlab at Grand Valley State University. This study showed how the inverted method not only allowed the students to understand and practice content, but it also prepared them to be better learners. Thomas ${ }^{11}$ performed the first implementation of the inverted class in a Mechanics of Material course at Missouri University of Science and Technology. This study indicated that the flexibility provided by the flipped method allowed for improvement in the quality of the instruction. In addition, this method provided a tool enabling the instructor to understand considerably more about each student's abilities. Lemley et al. ${ }^{12}$ used the inverted classroom in a Thermodynamics class at the University of Central Oklahoma. This study showed both qualitative and quantitative differences with classical methods, especially on homework assignments and final exams.

The aim of this study is to present the changes that the author has implemented in a 200 level Computer Methods for Engineering class. These changes have been put into effect to overcome issues which have been ascertained by the author and to improve the student overall understanding of the material. This study will compare the impact of the changes using the learning outcomes of the class. In addition, the study will present results of surveys that were distributed to current and past students.

\section{Description}

This section presents a description of the Computational Methods for Engineering class, the different challenges to teach it properly and the changes which have been implemented. The application of these changes is shifting the class towards a learner-based methodology.

\subsection{Class Description}

Computational Methods for Engineering is a 200 level engineering class that is aimed to teach students the tools for problem solving, graphing and analyzing engineering data, and programming techniques. The class uses Excel and Matlab as the software to implement these tools. The class starts with Excel in the first part of the semester and then continues with Matlab in the second part. The class has four contact hours per week, which are evenly divided into lecture and lab time. In general, the class size ranges from 18 - 20 students per section. 


\subsection{Challenges}

The following is a list of the most significant challenges that the author has encountered while teaching this class:

- Disconnect between the topics covered in Excel and Matlab.

- Insufficient time during class to cover all the materials with the desired depth and to provide multiple examples.

- Insufficient time during class for students to practice their homework assignments with the instructor's support.

- Ability to provide substantial feedback to each student's homework assignment.

- Different academic backgrounds, software knowledge and learning skills.

\subsection{Changes}

A series of changes have been implemented progressively during the last four semesters to address these challenges. The following is a detailed description of the changes.

\subsubsection{Class Structure}

Initially, Excel was introduced at the beginning of the semester and Matlab in the second part. The main idea about this structure was that students would learn the tools of each software independently, while avoiding confusion between them. However, the author found that this method did not allow for an effective way of comparing the tools between Excel and Matlab. The new structure of the class is based on topics. For example, the first seven lectures introduce the fundamental concepts and techniques in Excel and Matlab, which will be used later in the semester. The next series of lectures apply the techniques mentioned previously in the following different topics: Programming, plotting, curve-fitting and interpolation, solving single equation, solving system of equations, integration, and statistical analysis. The general outline of these lessons starts with an introduction to the topic, followed by the methods to solve it in both Excel and then Matlab. Later, a comparison is done between the different methods, so that the student can observe the advantages and disadvantages of each. The student is able to determine which method is more accurate and convenient.

\subsubsection{Homework Assignments Structure}

Originally the homework assignments were extracted from the two different textbooks. The problems covered the techniques in each software; however, they lacked a connection to compare the results. This created a disconnect between the new class structure and the homework assignments. Therefore, the author created a handout with problems to be solved using techniques of both Excel and Matlab. In addition, for many of these problems, students were required to 
provide written comparison of their results. Solving the same problem with different options serves a dual purpose: First, students can validate their own results, therefore creating a pattern of self-evaluation and immediate feedback. Second, it switches the class towards a learner-center environment, moving students toward a more successful professional practice.

\subsubsection{Collection Method for Homework Assignments}

Initially, homework was collected via email at the end of each week. The students received a feedback in writing, which included description of errors and suggestions. The author noticed, that in many cases the students did not review the feedback. Therefore, they did not correct the errors or apply the suggestions. In addition, the same type of errors found in the homework assignments were noticed during the exams. It was clear that a new method of correcting the assignments was necessary. The author developed a method by which the assignments are revised by the instructor in each student's computer. Once the student has completed one or all the assignments of a lecture, then the instructor proceeds to the computer. If the problem is complete and correct, the instructor stamps the student's assignment sheet. However, if there is an error, the instructor explains to the student how to correct the error, and the student may resubmit the problem before the deadline.

This method has been proven to be an effective tool to provide immediate feedback to each student. In addition, the instructor is able to capture fundamental mistakes and correct them in time. The main disadvantage of this method is that it requires more class time to properly address the needs for all of the students.

\subsubsection{Teaching Pedagogy}

The original format of the class followed the classical pedagogy in which the instructor teaches a lesson, presents some examples and students complete homework assignments partially in class time and the rest on their own. As indicated in the previous section, this format is not conducive for the new method of homework collection. After some research, the author found a learning pedagogy which potential could be an excellent fit for this class. This pedagogy was the "flipped" or inverted classroom. In essence, this format provides the lectures in advance, so that the students can use the class time to complete their homework assignments. The author developed videos and power point presentations for each lecture. The videos serve as a simple and comprehensive tool to introduce each lecture. These videos follow the content provided by the power points, which allows the student to easily take notes. In addition, all the videos contain dynamic features to emphasize critical points and concepts, as a way to make each more interesting and engaging for the student. Each video also contains interactive quizzes after each section. Students must complete each quiz before moving to the next section. All quizzes must be completed before coming to class. Once the student comes to class, the instructor answers any questions about the lecture. Then the instructor reviews additional examples using the concepts introduced in the video. Lastly, the student has the remaining of class as lab time to complete homework assignments. The following is a description of the positive aspects of using the flipped method which have been observed by the author: 
- Previously, the class was evenly distributed between lecture and lab time. The new format allocates $80-90 \%$ of the class time for lab time, which allows the student to have more time to complete their assignment in class. This allows the instructor to allocate more time to each student correcting assignments and providing individual feedback.

- Students develop skills to manage their own learning process. They are fully responsible for their knowledge. They simply have to use the tools available to succeed.

- Students are able to watch the videos as many times as needed for them to review and reinforce concepts.

- Students can start and pause the videos, to meet their own schedule and availability.

- Students have the ability to stay in pace with the class, even if they have missed classes.

The most noticeable negative aspect of the flipped class, is that some students do not spend enough time outside class to learn or review the material, therefore, they do not take full advantage of class time to complete assignments.

\section{Results}

This section presents a description of the results used to evaluate the effectiveness of the changes implemented in the Computer Methods for Engineering class. The results are divided into two sections: First, a comparison of the impact of the changes in the learning outcome of the class over four semesters. Second, a series of surveys distributed to current and past students.

\subsection{Impact on Learning Outcomes}

The learning outcomes for the Computational Methods for Engineering class are described as follows:

Upon completion of class, the student will be able to use Excel and MATLAB to:

1. Develop engineering graphs, in both two and three dimensions.

2. Solve single and system of equations. (Linear and non-nonlinear)

3. Perform curve fitting and interpolation of engineering data.

4. Write programs to solve repetitive problems

In order to ascertain how the changes applied to the class impacted these outcomes, it is necessary to indicate the order of implementation. Table 1 shows the sequence of in which all the changes were put into effect during the last four semesters. 


\begin{tabular}{|c|c|}
\hline Semester & Changes \\
\hline Fall 2012 & Original format \\
\hline Spring 2013 & Class Structure \\
\hline Fall 2013 & Homework Assignments \\
\hline Spring 2014 & Collection Homework Assignments \\
\hline Fall 2014 & Teaching Pedagogy \\
\hline
\end{tabular}

Table 1: Sequence of implementation of changes in the Computational Methods for Engineering Class from Fall 2012 - Fall 2014

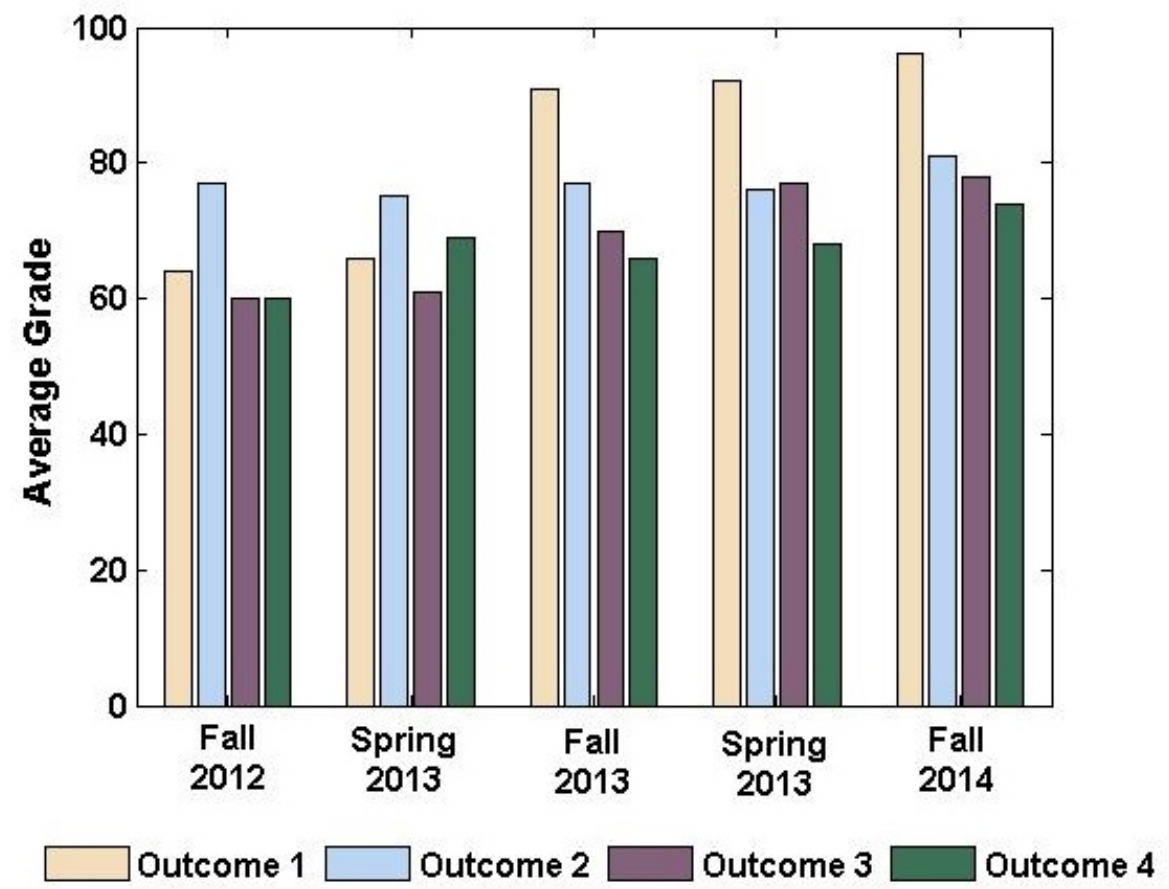

Figure 1: Impact of Changes on the Computational Methods for Engineering Class Outcomes from Fall 2012 - Fall 2014

In order to evaluate the impact of these changes, data was collected, evaluated, and analyzed over five different semesters. Figure 1 shows a summary of the data analysis from Fall 2012 to Fall 2014. As it can be seen from this figure, the average grades for the outcomes of Fall 2012 ranged from 60 to 77. This is the base line for the evaluation, since that semester had the original format. In general, the average performance in all outputs increased as more changes where implemented. The minimum change was for output 2, with an increase of $7 \%$ and the maximum was output 1 with a rise of $33 \%$. During the semester when all the changes were applied, the average grade for all the outcomes ranged from $74 \%$ to $96 \%$. These results are very encouraging, because they show that the implementation of the different changes has provided significant improvements in the average grade of the students. At the same time, these results show that there is plenty of room for advancement, especially for outcomes 3 and 4, which are currently below $80 \%$. 


\subsection{Surveys}

In order to evaluate the impact of the change on the student perception and experience, two different surveys were administered. The first survey was given to students from the class of Fall 2012 to Spring 2013 and the second was done at the end of Fall 2014.

\subsubsection{First Survey}

The aim of this survey is to better understand the challenges that students have encountered while taking the class and to better understand how the changes have improved their learning experience. For this survey, all the changes had been implemented as described in Table 1 except the flipped methodology. The following is a summary of questions of the survey and the most recurring responses. The survey was given to 90 different students.

Question 1: Did you review the material of each lecture before coming to the next class?

The purpose of this question is to determine if the students were proactive and were prepared before each lecture. As can be seen in figure 2 - A, only $13 \%$ of the students always review the material before the class. Unfortunately, most students do not realize the benefits of this practice, in order to fully take advantage of the lecture.

Question 2: Would you watch the videos of the lectures to review the material before coming to class?

The intention of this question is to gauge if the student would watch videos for lecture before coming to class. As shown in figure 2 - B, $50 \%$ of the students, they would take advantage of watching the videos. In addition, it shows that if the students have suitable tools, such as videos, they would be more motivated to review the material before coming to the class. This is a good trend, which indicates students would be more prepared before class and be more capable to start their assignments successfully.

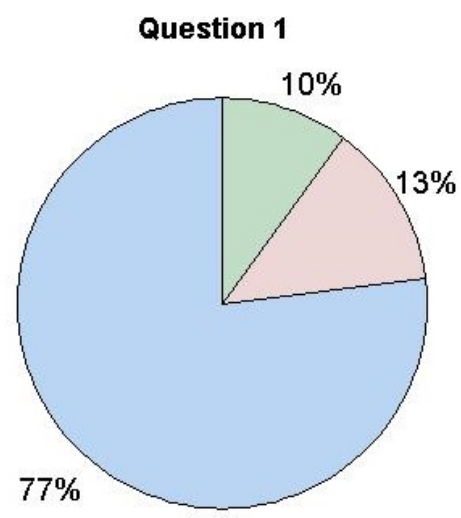

A

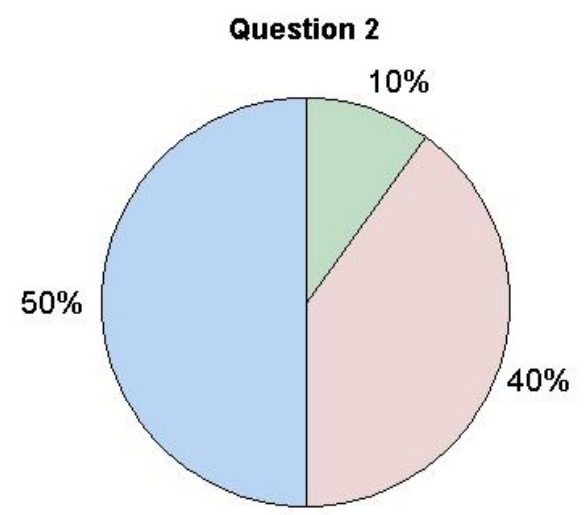

B

Sometimes Always Never

Figure 2: First Survey - Questions 1 and 2 
Question 3: After watching some of the videos created for this class, how would you feel about having these videos as the lectures and use the time in class to do more exercises instead?

The aim of this question was to see if previous students would find a benefit in using the videos as a method to provide the lectures, instead of the regular class structure that they had when taking the class. In general, the reactions were very positive as it can be seen from these samples answers:

- I think it is great idea. By doing more examples in the class it will definitely help to understand material better.

- Yes! I think it is a great ideal to use this method for this class. I had many questions while I was doing the exercise. I believe other students also need to ask the questions.

- I feel like the videos are very beneficial to the students because, because they will allow students to take as much time as they need to understand the topic at hand without disrupting the class.

- I think that it is an awesome idea. It is hard in class to watch what the instructor is doing and then do it yourself on the computer in front of you, and then try and catch up to the next thing the instructor does. This is a very good way to teach someone how to use the program because they can pause/rewind the video if they need to hear/see it again.

- I think the videos are a great tool to help both the student and the Instructor. The Instructor won't have to stop the class and wait for the slowest student to catch up, and the student won't have to be embarrassed to ask for help and make everyone wait. Perhaps the students could watch the videos on their own and then go to class and try to do the exercises and have the Instructor assist them if needed.

Question 4: In your experience in this class what was the most difficult component?

As can be seen in figure 3, the most common responses were doing homework and review concepts on their own. These difficulties are addressed by flipping the class, therefore allowing students to complete their homework with the assistance of the instructor.

Question 5: Do you think it is beneficial for students taking this class to have exercises corrected individually in their computer?

The purpose of this questions is assess if the new method of collecting homework is helpful. All the students were in agreement with the new methodology. These are few responses from students:

- Yes, this class for me was best learned when I would perform problems on my own and have the professor tell me as an individual what I was doing wrong and how to get it correct. I believe most students learn best one on one rather then being talked to as a class.

- Yes, i do that way they can see what they are doing wrong and try to learn the material better.

- Yes, it is very difficult to see the small errors in the homework problems for this course. It's always easier to compare the answers with peers or have the professor look at them. 

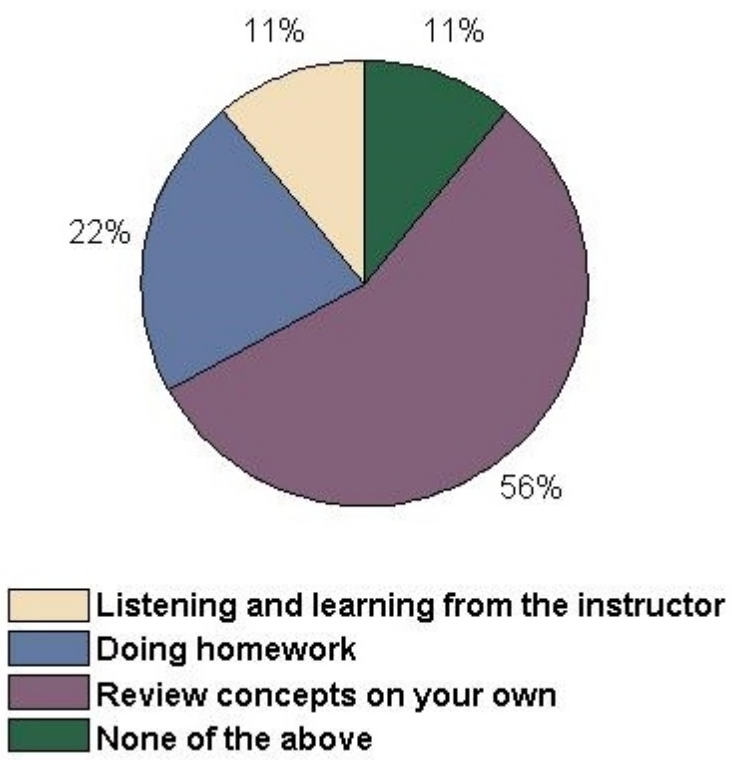

Figure 3: First Survey - Question 4

Question 6: If you ever miss a class, what did you do to cover the material?

The goal of this question was to understand what steps the students take when they are absent and to determine if the flipped method would be valuable in this respect. The following are some of the answers from students:

- I read the material on my own and attempted the homework on my own. When problems arose, I consulted the professor for assistance.

- Read the material that was covered during the missed class and do practice problems. Go to professors office hours to clarify what you missed.

- I did practice examples from the assigned book. I also tried to get notes from a classmate to see what concepts are emphasized

- Follow up with Professor and got class notes.

- Usually nothing, I hope I can learn it the next lecture. A very bad habit, I do admit. I intend to now review it over with a classmate, and do readings that may cover the topics I missed in class.

- Look at the corresponding sections in the book(s) that I missed, and Google anything I'm unsure about.

- I generally ask the professor what I miss. Then I go home and review the material. If I am confused with any of the material then I'll come back and ask questions.

- Watch topic on You Tube and work through problems on my own.

In general, students do not have a well-established method to cover missed material. This can potentially create a gap in their class progress, which may increase over time. Fortunately, the 
flipped method allows the students to have lectures always available, therefore minimizing the impact of absences have in their learning process.

Question 7: Do you think it is better to learn Excel and Matlab separately? Or it is better to learn them based on topics, such as plotting, finding roots, integration, etc.

The aim of this question is to evaluate if the new class structure is beneficial for students. For most of the students, the new structure is more advantageous. However, there are some students who believe learning the software separately is better, due to the higher complexity of Matlab compared to Excel. These are sample responses from students:

- I think it would better to learn the topics side by side so the students can get an understanding of how to do the same thing in both programs. It might be a bit confusing at first to switch programs, but I think it might be better for the students.

- I think that it is better to learn them based on topics because then you can compare their advantages and disadvantages.

- I believe that learning these two interfaces separately was best in my own experience, because Matlab was a handful while I was more accustom to using excel. So while I expanded my horizon on excel learning Matlab separately eased the struggle.

- I think that separately is better. Matlab is very tricky to use and to have to switch my brain from one to the other would be difficult.

As it can be seen from the results of this survey, the changes implemented so far (structure of class and homework assignment, and collection method), have yielded a positive support from most of the students. However, there are still some issues that need to be addressed such as: preparation before class, covering the material after an absence, and to devote more time for one-one-one interaction with the students. It is the goal of the author to show, that these issues can be solved by the use of the flipped method.

\subsubsection{Second Survey}

The purpose of this survey is to evaluate the effectiveness of the implementation of the latest change; the use of the flipped methodology. The survey was given to 30 different students.

Question 1: The Flipped classroom is a new concept in the Engineering Department, do you feel that it helped you learn the material of this class?

Question 2: Was the class set up helpful in your learning? Watching videos as homework, working in class on problems?

The purpose of these questions is to evaluate the effectiveness of the new class learning method, using the flipped method. As it can be seen in figure 4, the majority of the students either agree or strongly agree with the new methodology of the class. Only $10 \%$ of the students disagree with the new class pedagogy. 
In addition, these are some of the comments of the students of how the flipped method help them learning the material of the class.

- It gave me a better understanding because the material was discussed twice, once in the videos and another time in class.

- It gave me the material prior to arriving for class.

- The flipped class gave me a clear walk through on how to use the commands, and once in the class, I was able to use those commands effectively.

- It was helpful to see the subject before class, it make easy to understand the explanation in class

- Having the teacher there for immediate help was extremely helpful.

- Time with the professor wasn't wasted on a boring lecture but instead perfecting our skills with the professor.

- It helped me understand the lesson better since it was more on my own.

- I found the flipped class very helpful because it allowed me to take notes at my own pace while the lecture video progressed. If I had missed something I could pause or rewind the video to clarify.

- Being able to work with professor in class helped a lot as well as the videos being well done and in depth.

- I think it made learning easier. I find it easier to learn material when I can be helped immediately when I come across an issue while doing the work.

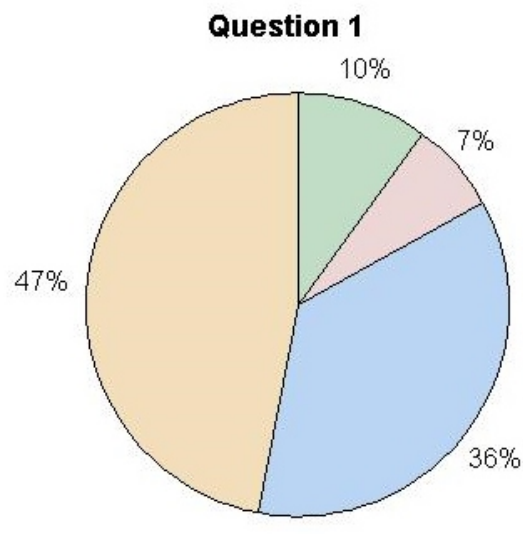

A

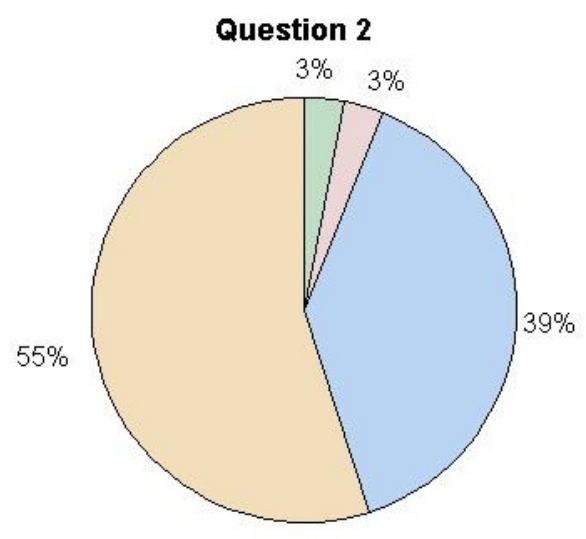

$\mathbf{B}$ Strongly Agree $\square$ Agree $\square$ Undecided $\square$ Disagree

Figure 4: Second Survey - Question 1 and 2

Question 3: Please describe the amount of effort you put in learning the material for the class at home? 
The goal of this question is to measure the amount of effort the student is putting in watching the videos and reviewing the material. As it is shown in figure 5 - A, most of the students are putting good or maximum effort into the class. In average, students are dedicating between 2 to 4 hours per week outside the classroom.

Question 4: How confident did you feel about the material after watching the video(s) but before coming to class to do the problems?

The aim of this question is to measure the level of confidence of the students after watching the videos. As can be seen in figure 5 - B, the majority of the students felt somewhat confident. This indicates, that additional work needs to be done in this area, to ensure the students increase their confidence level about the learned material, so that they can take full advantage of the videos and the class time.

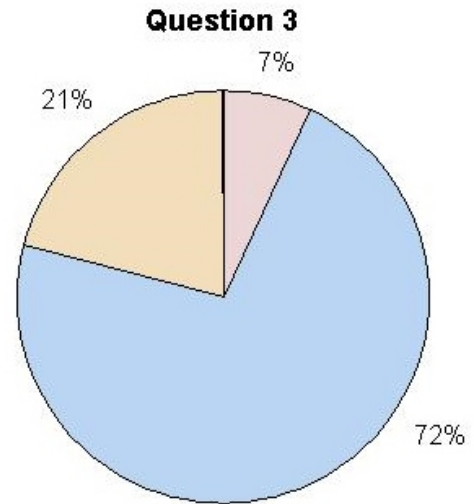

A

Maximum Effort Good Effort Little or No Effort
Question 4

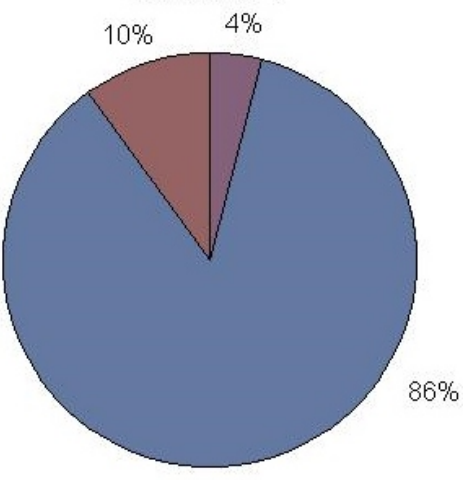

B

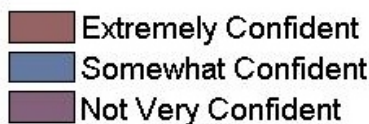

Figure 5: Second Survey - Question 3 and 4

Question 5: What activities did you perform while watching the videos?

The purpose of this question is to check what activities the students are doing while watching the videos. As it is shown in figure 6 , the most common activities were: take notes, stop when needed and re-watch sections. These results demonstrate that the primary goals of the flipped methodology are being accomplished successfully.

Question 6: Did the videos cover the material properly?

This question was aimed to find out the opinion of the students about the content of the videos. The following are some of the responses given.

- Yes, the material was exactly what we needed for the following week

- They cover the material for the assignments and what we were tested on.

- The videos covered the material, but some could have been more detailed. 


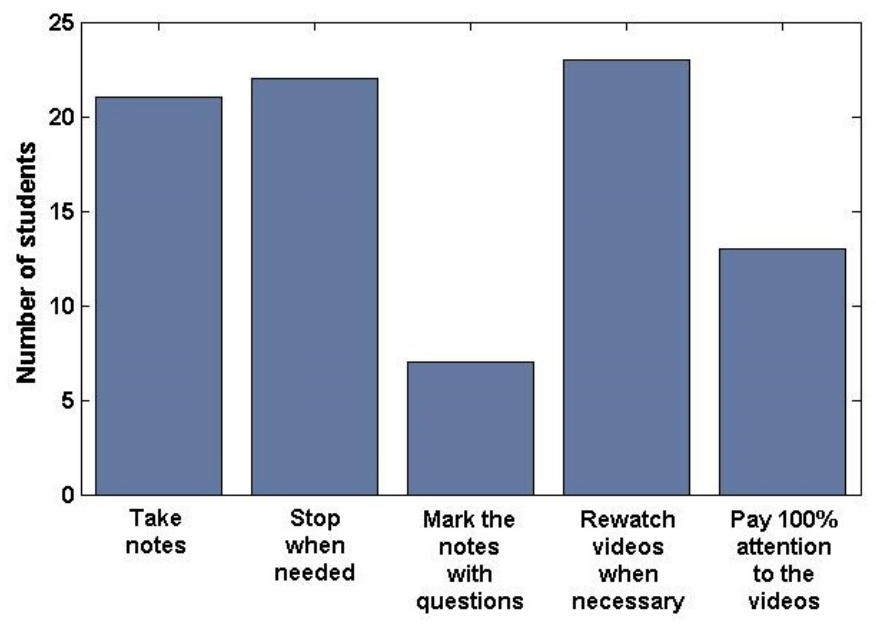

Figure 6: Second Survey - Question 5

- The video covered the material to the letter, everything the instructor wanted us to learn was covered in the videos.

- It might have been too-detailed while watching it, but when it came to actually performing the tasks in the video it made sense to know the small details.

- The videos covered all of the material, sometimes I would disregard a note, or what I thought was a subtle anecdote, that turned out to be vital to the core concept of a lesson.

- They covered the material thoroughly, however ones that were on the longer side were hard to stay focused on without getting distracted.

- Videos covered everything. Some cuts could be made to shorter it and keep attention to the viewer

Most of the videos are currently between 15 - 20 minutes. However, there are few which are 30 40 minutes long. The feedback provided by the students indicate that the length and engagement level of some of these videos has to be revised.

Question 7: What could the instructor do for the students to help support them more in the flipped Classroom?

This question was done to find out suggestions or things that need to be changed to improve the class. These are some of the responses.

- A more interactive video, maybe take the quiz in a shorter period of time when listen to the lecture, to make sure the student is keeping up with the lecture.

- I think a flipped class would benefit greatly from the help of a TA during class hours. This way, if the student cannot get the instructor's full attention, he/she can call on the TA to help with quicker conceptual questions that the instructor may have already covered and understandably, would not want to repeat.

- Nothing, I really enjoyed it and wish that all my classes were like that. 
- I don't think its possible to offer anymore support than being available while the students are doing the homework

- I thought everything went perfect. If a student received poor marks it is only their own fault. Assignments and due dates were clearly stated. As long as a student did what they were suggested to do than they should have done great in the class.

- Nothing, you already provide lecture notes and examples within the videos. It is hard to do bad as long as you are completing all of the work.

\section{Question 8: Would you like to take other flipped class?}

This aim of this question was to gage if students would like to experience another flipped class. $90 \%$ of the students had a positive response, and would entertain the possibility of taking another flipped class if it is available.

In general, the results of this survey indicate that for the most part, students are in favor of the of the new teaching pedagogy. There are however, very significant suggestions that need to be taken into consideration in order to improve the quality of the learning experience.

\section{Conclusion}

The Computational Methods for Engineering class has gone through a sequence of changes in the last four semesters. The intention of applying these changes is twofold: First, to tackle the challenges found while teaching the material. Second, to switch the class toward a learner-based approach. The ultimate goal of modifying the class is to improve the learning experience of the students and to enhance their knowledge in order to be successfully used in a professional setting.

The following are some key points that need to be explored in the near future to maintain the positive trend of students' success in the class.

- Review and modify videos to ensure that their length, content, and engagement level are conducive for students' learning.

- Develop new activities to increase the level of confidence of students after they watch the videos and before they come to class.

- Develop new activities to address the low performance in learning outcome number 4 (Programming). This topic is the most challenging component in the curriculum. Ideally, multiple weeks should be devoted to it, however this is not possible due to time constraints. Therefore, it is necessary to develop additional resources to be specifically tailored to accommodate for the challenges of this topic.

- Modify the current assessing tools in order to obtain more detailed student-performance data to identify the specific topics that make students struggle the most. Once, these topics are isolated, additional activities must be created to address the difficulties. 
- Collect more data and develop a more comprehensive statistical analysis to validate the significance of the implementation of the changes.

As a whole, the application of the different changes had a positive effect in the learning experiences. The results provided in this study showed a favorable trend between the application of the changes and the performance of the students. Nevertheless, additional data analysis is required to corroborate these findings.

This is the first class in the Engineering Department that uses the flipped pedagogy. Using the positive results from this implementation, the author expects that many other classes will follow suit.

\section{References}

[1] Litzinger T. A., Lattuca L. R., Hadgraft R. G. Newstetter W. C. Engineering Education and the Development of Expertise. Journal of Engineering Education January 2011; 100: 123-150.

[2] Albanese M. A., Mitchell S. Problem-Based learning: A Review of Literature on its Outcomes and Implementation Issues. Academic Medicine 199368 52-81.

[3] Yadav, A., Subedi, D., Lundeberg, M., Bunting, C. F. Problem-based Learning: Influence on Students' Learning in an Electrical Engineering Course. Journal of Engineering Education 2011;100: 253-280.

[4] Prince M.J., Felder R.M. Inductive Teaching and Learning Methods: Definitions, Comparisons, and Research Bases. Journal of Engineering Education 2006; 95: 123-138.

[5] Bishop J.L., Verleger M. A. The Flipped Classroom: A Survey of the Research Proceedings, American Society for Engineering Education. Atlanta. June 2013.

[6] Lage M.J., Platt G.J. , Treglia M. Inverting the Classroom: A Gateway to Creating an Inclusive Learning Environment. Journal of Economic Education 2000; 31: 30-43.

[7] Gannod, C., Burge, J., Helmick, M. Using the Inverted Classroom to Teach Software Engineering. Proceedings, 30th International Conference on Software Engineering. Leipzip, Germany. May 2008.

[8] Toto R., Nguyen H. Flipping the Work Design in an Industrial Engineering Course. Proceedings, 39th ASEE/IEEE Frontiers in Education Conference. San Antonio. October 2009.

[9] Zappe, S., Leicht, R., Messner, J., Litzinger, T., Lee, H.W. "Flipping” The Classroom to Explore Active Learning in a Large Undergraduate Course. Proceedings, American Society for Engineering Education. Austin. June 2009.

[10] Talbert, R. Learning Matlab in the Inverted Classroom. Proceedings, American Society for Engineering Education. San Antonio. June 2012.

[11] Thomas, J. An Inverted Teaching Model for A Mechanics of Material Course. Proceedings, American Society for Engineering Education. San Antonio. June 2012.

[12] Lemley, E. C., Jassemnejad, B., Judd, E., Ring, B. P., Henderson, A. W., Amstrong, G. M. Implementing a Flipped Classroom in Thermodynamics. Proceedings, American Society for Engineering Education. San Antonio. June 2012. 